\title{
Scientific Conferences as a Medium of Academic Communication - a Case of INFuture
}

\author{
Nikolaj Lazić*, Ivan Dunđer ${ }^{* *}$ \\ *Department of Phonetics \\ ** Department of Information and Communication Sciences \\ Faculty of Humanities and Social Sciences, University of Zagreb \\ Ivana Lučića 3, Zagreb Croatia \\ nlazic@ffzg.hr, idundjer@ffzg.hr \\ Marko Odak \\ Faculty of Philosophy, University of Mostar \\ Matice hrvatske b.b., Mostar, Bosnia and Herzegovina \\ odakmarko@yahoo.com
}

\section{Summary}

Scientific conferences provide opportunities for both formal and informal communication of academic insights among conference participants and make possible the sharing of those insights with the wider academic community as well as the wider public through the publication of conference papers in both print and digital form, and owing to all this they may be considered a significant medium of academic communication. Every system of communication consists of three basic elements: source of information, information user(s) and mediums or channels used for disseminating information. We analysed the system of academic communication using this basic structure, where we approached scientific conferences as a medium used for the dissemination of information. However, it is important to emphasise that in this basic scheme researchers represent the source of information and information users at the same time. Our analysis of academic communication includes both the dissemination and assimilation of scientific information taking place at conferences.

Standard forms of activity and interaction at scientific conferences, ranging from oral communication during the giving of presentations, through written communication involved in the publication of papers as part of conference proceedings to one's very presence at a conference, should carefully be evaluated in terms of their effectiveness as mediums of academic communication.

We will present the results of our preliminary research through demonstrating correlations between the number of authors and number of papers presented at previous INFuture conferences, classifying authors by country, co-authorship, etc., and thus provide an introduction into a more detailed research into the communication space created as a result of scientific conferences and the role of that space in the communication within a particular academic community. 
A more extensive research project will include scientometric and bibiliometric analyses, interviews and comparative analyses that should provide us with insights into the significance of conferences as a medium of academic communication and their impact on the academic community.

Keywords: academic communication, evaluation of scientific work, conferences as a medium of academic communication, INFuture

\section{Introduction}

Science, as a complex human activity, is based on the innovative work of scientists and researchers and a subsequent dissemination of insights resulting from their work. If we approach science as a process based on research activity and the accompanying communication of research results, then scientific conferences and conference publications may be regarded as a multi-directional communication channel.

Every system of communication consists of three basic elements: source of information, information user(s) and mediums or channels used for disseminating information. We analysed the system of academic communication using this basic structure, where we approached scientific conferences as a medium used for the dissemination of information. However, it is important to emphasise that in this basic scheme researchers represent the source of information and information users at the same time. Our analysis of academic communication includes both the dissemination and assimilation of scientific information taking place at conferences.

Researchers are constantly searching for new information relevant for their work and keep publicising the results of their research and analyses, first in the form of various oral or written reports and subsequently as published academic papers. These two roles of researchers are so heavily intertwined that it is difficult to analyse them separately. It is particularly hard to distinguish between dissemination and assimilation of information when it comes to informal types of communicating knowledge. Thus when researchers give presentations at a conference, they both provide information and seek for new information in the form of comments of their colleagues and the acceptance or rejection of the ideas that they put forward.

Personal encounters and conversations on themes and issues being discussed at a conference are also very significant, regardless of possibilities provided by means of online communication.

\section{Methodology}

As the main source of data on conference papers, authors and their institutions, authors' countries of origin, themes and keywords we used digital conference proceedings, which we first analysed separately and then proceeded to make comparisons. 
We wanted to use the results of the comparative analysis of the four years of INFuture conferences to extract data that we would subsequently use as the basis for further research on the value of academic communication taking place at conferences and the resulting connections realised as various types of personal and institutional cooperation. Since we hold that a more detailed research on the communicational value of conferences is necessary, this preliminary research represents a basis for the formulation of hypotheses on the value of academic communication occurring at conferences and of the communication space that they create.

The obtained data have been structured and interpreted as part of the Results and Interpretation chapter. They were analysed according to the following parameters: participating countries, number of authors, participating institutions and cooperation between authors.

\section{Results and interpretation}

We analysed the extracted data and will present them by the parameters stated above.

\section{Participating countries}

The sole number of countries represented at the conference since its beginning is highly significant since it provides insight into the size of the communication space created by the conference (Table 1). The conference's second year brought about the expansion of that space and the inclusion of a larger number of participating countries.

Table 1: Number of participating countries

\begin{tabular}{|l|c|c|c|c|}
\hline & $\mathbf{2 0 0 7}$ & $\mathbf{2 0 0 9}$ & $\mathbf{2 0 1 1}$ & $\mathbf{2 0 1 3}$ \\
\hline Number of participating countries & 11 & 13 & 11 & 6 \\
\hline
\end{tabular}

Table 2: Number of conference participants by country

\begin{tabular}{|l|l|l|l|}
\hline $\mathbf{2 0 0 7}$ & $\mathbf{2 0 0 9}$ & $\mathbf{2 0 1 1}$ & $\mathbf{2 0 1 3}$ \\
\hline Croatia (98) & Croatia (145) & Croatia (64) & Croatia (46) \\
Slovenia (5) & UK (5) & Serbia (6) & USA (2) \\
UK (2) & Slovenia (5) & Finland (5) & Canada (2) \\
Italy (2) & China (3) & Germany (3) & Germany (1) \\
Czech Republic (2) & Germany (3) & Turkey (2) & Australia (1) \\
Bosnia and & India (3) & Slovenia (2) & Netherlands (1) \\
Herzegovina (2) & USA (2) & Norway (2) & \\
Poland (2) & Iran (2) & Portugal (2) & \\
Nederlands (1) & Italy (2) & China (1) & \\
Australia (1) & Bosnia and Herzegovina (2) & Ireland (1) & \\
Ireland (1) & Netherlands (1) & Switzerland (1) & \\
Lithuania (1) & Serbia (1) & & \\
& Belgium (1) & & \\
\hline
\end{tabular}


Data on the conference's third and fourth year show that the number of participating countries decreased, which may be attributed to social and economic conditions in some countries. This decline also brings us to the issue of the sufficiency of financial resources provided by academic institutions or ministries for conferences as a medium of academic communication.

Table 2 shows that majority of authors are from Croatia.

A questionnaire survey that would include the majority of conference participants since the launching of the conference should be carried out as part of a comprehensive research in order to gain insight into these circumstances.

\section{Number of authors}

The analysed data show an increase in the number of authors between the first and second conference year (Table 3). However, a marked decline in this number is observable in the third and fourth conference year.

Table 3: Number of authors by conference year

\begin{tabular}{|c|c|c|c|c|}
\hline & $\mathbf{2 0 0 7}$ & $\mathbf{2 0 0 9}$ & $\mathbf{2 0 1 1}$ & $\mathbf{2 0 1 3}$ \\
\hline Number of authors & 117 & 175 & 89 & 53 \\
\hline
\end{tabular}

Reasons for such decline surely have to do with the economic crisis that befell countries in the region and the related insufficiency of public resources provided for education and science.

\section{Participating institutions}

We considered this category important for several reasons. First we wanted to gain insight into the type of institutions that authors came from and subsequently analyse if there were any institutions that stood out or were in any way 'unexpected' (as foundations under 'others' in Table 4). The analysis showed that the majority of participating institutions were educational and scientific institutions. Apart from them, authors at the first conference also came from libraries, archives, museums and government institutions and agencies.

Table 4: Participating institutions grouped by type of institution

\begin{tabular}{|c|c|c|c|c|}
\hline & 2007 & 2009 & 2011 & 2013 \\
\hline Libraries & $8(6.8 \%)$ & $11(6.3 \%)$ & $8(9.0 \%)$ & $1(1.9 \%)$ \\
\hline Archives & $2(1.7 \%)$ & $1(0.6 \%)$ & $1(1.1 \%)$ & $0(0.0 \%)$ \\
\hline Museums & $0(0.0 \%)$ & $1(0.6 \%)$ & $2(2.2 \%)$ & $0(0.0 \%)$ \\
\hline $\begin{array}{l}\text { Faculty, university, } \\
\text { institute }\end{array}$ & $82(70.1 \%)$ & $136(77.7 \%)$ & $75(84.3 \%)$ & $41(77.4 \%)$ \\
\hline Industry & $4(3.4 \%)$ & $6(3.4 \%)$ & $1(1.1 \%)$ & $5(9.4 \%)$ \\
\hline Government agencies & $11(9.4 \%)$ & $10(5.7 \%)$ & $1(1.1 \%)$ & $3(5.7 \%)$ \\
\hline Other & $\begin{array}{r}10(8.5 \%) \\
\text { foundation (2) } \\
\text { elem. school (2) } \\
\text { sec. school (1) } \\
\text { unknown (5) }\end{array}$ & $\begin{array}{r}10(5.7 \%) \\
\text { freelance }(3) \\
\text { foundation }(2) \\
\text { elem. school (2) } \\
\text { association (1) } \\
\text { unknown (2) }\end{array}$ & $\begin{array}{r}1(1.1 \%) \\
\text { sec. school (1) }\end{array}$ & $\begin{array}{r}3(5.7 \%) \\
\text { elem. school (3) }\end{array}$ \\
\hline
\end{tabular}




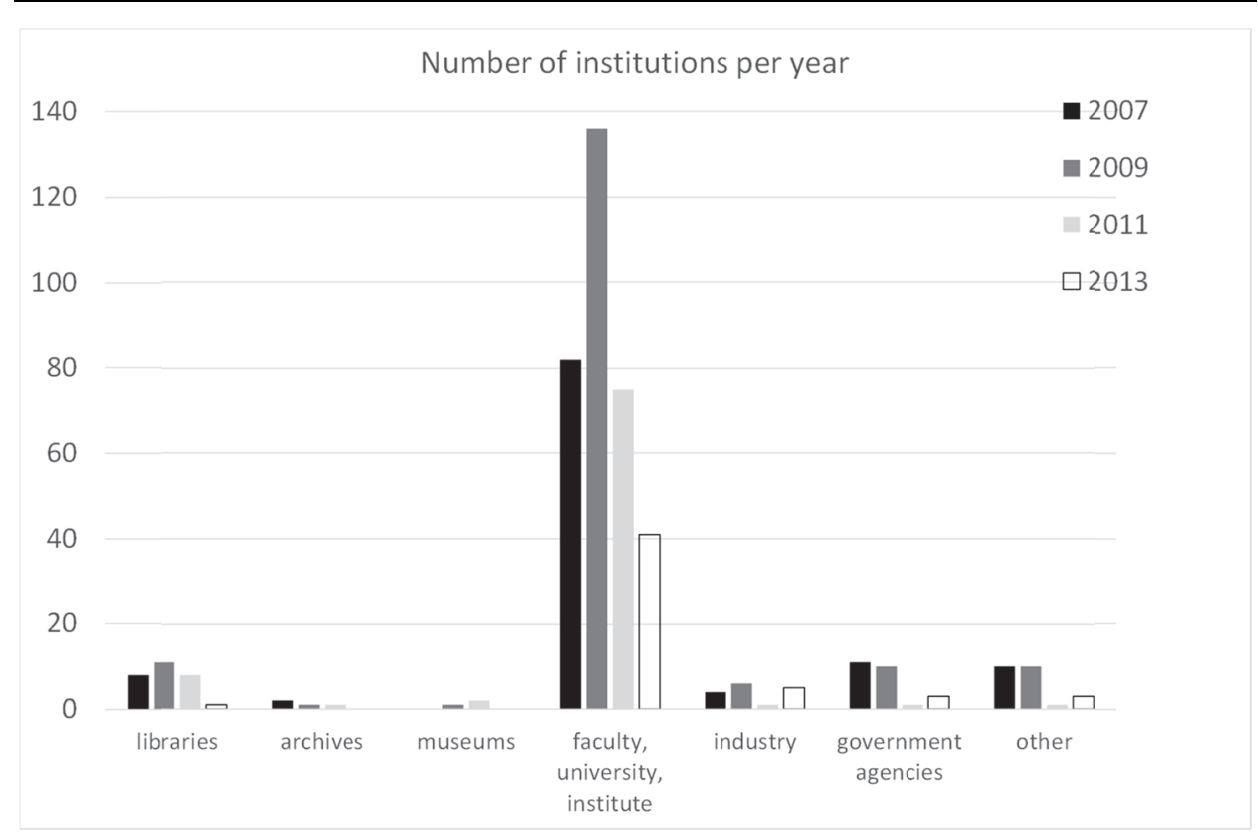

Figure 1. Participating institutions grouped by type of institution

Data for the conference's second year show that an already large number of conference participants coming from educational institutions in the conference's first year increased even further (Figure 1). Such tendencies are not surprising if we take into consideration that the programme of the conference addressed themes and issues related to changes in the curricula of many LIS-oriented study programmes. In our more comprehensive research we will use these indicators to examine the hypothesis that conference's significance in the realm of academic communication is significantly affected by institutions that authors of conference presentations come from.

\section{Cooperation between authors}

The concept of cooperation implies the joining of efforts and activities and this aspect should be analysed both at the level of personal cooperation between individual researchers and between institutions. Since we hold that the establishment of cooperation is one of the tasks of a scientific conference, a more comprehensive research should include interviews and questionnaires that would provide us with insight into the extent to which the existing connections and cooperation initiatives came as a result of the conference. Co-authorship is a form of intellectual cooperation, so we approached it as an indicator of cooperation. 
Table 5: Number of papers grouped by authorship

\begin{tabular}{|l|c|r|r|r|}
\hline & $\mathbf{2 0 0 7}$ & $\mathbf{2 0 0 9}$ & $\mathbf{2 0 1 1}$ & \multicolumn{1}{c|}{$\mathbf{2 0 1 3}$} \\
\hline Number of accepted papers & 56 & 77 & 43 & \multicolumn{1}{|c|}{25} \\
\hline Single author & $20(35.7 \%)$ & $21(27.3 \%)$ & $18(41.9 \%)$ & $8(32.0 \%)$ \\
\hline Two authors & $16(28.6 \%)$ & $19(24.7 \%)$ & $11(25.6 \%)$ & $10(40.0 \%)$ \\
\hline Three authors & $17(30.4 \%)$ & $33(42.9 \%)$ & $11(25.6 \%)$ & $4(16.0 \%)$ \\
\hline More than three & $3(5.4 \%)$ & $4(5.2 \%)$ & $3(7.0 \%)$ & $3(12.0 \%)$ \\
\hline More than two & $36(64.3 \%)$ & $56(72.7 \%)$ & $25(75.8 \%)$ & $17(68.0 \%)$ \\
\hline
\end{tabular}

Our analysis demonstrates the relationship between single-author papers and papers by several authors which remained constant throughout all four years of the conference (Table 5), with a percentage of single-author papers ranging from $27 \%$ to $41 \%$ and a percentage of papers by several authors shifting between $59 \%$ and $73 \%$. The predominance of co-authored papers indicates a strong tendency towards the joining of efforts between individual researchers and institutions and further fostering of connections established as a result of the conference as a dynamic context for communication.

Academic cooperation is a subject that has to be looked at separately and we should analyse in greater detail the extent to which various cooperation initiatives were prompted by the conference. Researchers and specialists in various fields use conferences to exchange their academic experiences and present their institutions and countries of origin. Thus specific instances of academic cooperation may be categorised as instances of personal cooperation between authors sharing similar research interests or as instances of institutional cooperation. A thorough analysis of a cooperation network spawned by INFuture conferences that would be carried out as part of a more comprehensive research opens up many possibilities but also necessitates carefully constructed in-depth interviews that would ensure the reliability and objectivity of data interpretation.

\section{Conclusion}

Scientific conferences as a medium of academic communication are affected by a wide range of circumstances. Some of them are related to specific characteristics associated with a given scientific field (Lazić, et al., 2013), area or discipline (Nederhof, 2006), while others are related to academic policies and official strategies (Mali, 2010; Abramo, et al., 2013; Bornmann, 2012). Rapid changes in the field of LIS (Lasić-Lazić, et al., 2013; Jokić, et al., 2012; Andreis et al., 2008) and LIS-related scientific disciplines, along with growing requirements for the dissemination of information, sharing of ideas, innovative solutions and more frequent and productive professional encounters and exchanges are making scientific conferences a significant context for and medium of academic communication. In our research we sought to reinforce the INFuture conference's significance as a medium of communication within LIS-oriented academic community and formulate hypotheses for our further research. 
Why should the publication of papers as part of conference proceedings be included among the criteria for academic advancement? Apart from citation databases today there is also the Thomson Reuters Conference Proceedings Citation Index and its Social Science \& Humanities collection, serving as a multidisciplinary bibliographic and citation database for this type of publications. However, since this is a commercial product that is not readily available to small academic communities, such publications cannot easily be subjected to scientometric analyses, so their evaluation has so far been relatively subjective, i.e. based on individual assessment. Information and insights in the field of library and information sciences quickly become outdated (Lasić-Lazić et al., 2013), so conferences have great importance as a medium of publicising these information, insights, data and ideas and having them either accepted or rejected by other partakers in the academic field. Furthermore, publishing papers as part of conference proceedings is currently growing in importance owing to long periods that researchers have to wait for their papers to be published in scientific journals. For example, the publication of papers in some LIS-oriented scientific journals sometimes takes as long as two years. Many data and insights become outdated during this period which makes conferences, as a context prompting and enabling a dynamic interaction between researchers in a given academic field, an even more significant medium of academic communication. The publication of a bibliography of conference papers would greatly contribute to the dissemination of knowledge and productive academic communication, therefore it should always accompany the publication of conference proceedings (regardless of the fact that some online services (e.g. Google Scholar) are already "compiling" one such huge bibliography).

Our research provided us with data demonstrating that personal cooperation between researchers and institutional cooperation feature as an important communicational element. A closer look at a varying number of authors and papers may lead us to the analysis of various economic and social factors influencing the development of the conference from year to year. The number of conference participants coming from LIS-oriented educational institutions indicates the significance of INFuture conferences for the development of the field of library and information sciences, especially librarianship.

Since the structure of communication associated with scientific conferences includes both formal and informal activities ranging from the first stages of research that a conference paper will be based on, to the actual presentation, the paper's publication as part of conference proceedings and the integration of its content into the corpus of the given academic discipline or field, it is clear that a more comprehensive research that would encompass all these aspects is necessary, and the results of our preliminary analyses provide a useful introduction into such research. 


\section{References}

Andreis, Mladen; Jokić, Maja. An impact of Croatian journals measured by citation analysis from SCI-expanded database in time span 1975-2001. // Scientometrics, 75 (2008), 2, 263-288.

Bornmann, Lutz. The Hawthorne effect in journal peer review // Scientomerics, 91 (2012), 3, 857862.

Jokić, Maja; Zauder, Krešimir; Letina, Srebrenka. Karakteristike hrvatske nacionalne i međunarodne znanstvene produkcije u društveno-humanističkim znanostima i umjetničkom području za razdoblje 1991-2005. Zagreb : Institut za društvena istraživanja u Zagrebu, 2012.

Lazić, Nikolaj; Lasić-Lazić, Jadranka. Analysis of Scientific Activities in the Field of Information Science: the Case of Croatia. // Medijska istraživanja. 19 (2013), 1; 5-18.

Lasić-Lazić, Jadranka; Pečarić, Đilda; Lazić, Nikolaj. The Network Map of the Fields of Interest in Information Sciences in Croatia // Recent Advances in Information Science. Proceedings of the 4th European Conference of Computer Science (ECCS '13) / Maurice Margenstern, Kleanthis Psarris, Danimir Mandic (ed.). Paris : WSEAS Press, 2013. 251-257.

Mali, Franc. Problemi javnih politika prema međunarodnoj produktivnosti i vidljivosti društvenih znanosti u zemljama Srednje i Istočne Evrope. // Sociologija i prostor, 48 (2010), 39, 415-430.

Nederhof, Anton J. Bibliometric monitoring of research performance in the social sciences and the humanities: A review. // Scientometrics, 66 (2006), 1, 81-100. 